\title{
EFEKTIVITAS TERAPI KOMPRES HANGAT REBUSAN JAHE DENGAN KOMPRES DINGIN TERHADAP TINGKAT NYERI LANSIA YANG MENGALAMI OSTEOARTHRITIS (Studi Di Kelurahan Kaliwungu Kecamatan Jombang Kabupaten Jombang)
}

\author{
Yepi $^{1}$ Inayatur Rosyidah ${ }^{2}$ Rastia Ningsih $^{3}$ \\ ${ }^{13}$ STIKes Borneo Cendekia Medika Pangkalan Bun ${ }^{2}$ STIKes Insan Cendekia Medika \\ Jombang \\ 1email : yepi826@gmail.com, 2email : inrosyi@gmail.com, 3email : \\ rastianingsih@gmail.com
}

\begin{abstract}
ABSTRAK
Nyeri adalah keluhan utama yang sering dirasakan oleh penderita osteoartritis. Banyak alternatif yang bisa digunakan untuk mengurangi rasa sakit, salah satunya adalah metode non farmakologis yang kompres air hangat rebusan jahe dan kompres dingin. Penelitian ini memiliki tujuan untuk menganalisis perbedaan efektivitas terapi kompres hangat rebusan jahe dengan kompres dingin terhadap tingkat nyeri lansia yang mengalami osteoarthritis. Jenis penelitian pre eksperimen dengan desain pendekatan static group comparison. Populasi adalah semua lansia berusia $>60$ tahun dengan osteoarthritis di Kelurahan Kaliwungu yang berjumlah 76 orang. Teknik sampling yang digunakan adalah simple random sampling dengan instrumen lembar observasi. Data disajikan dalam tabel dan dianalisis dengan menggunakan uji Wilcoxon Test dan Mann Whitney Test. Pada kompres hangat rebusan jahe diperoleh skala nyeri tertinggi sebelum terapi nyeri sedang $(59,4 \%)$, setelah dilakukan terapi menjadi nyeri ringan (87,5\%). Pada kelompok terapi kompres dingin diperoleh skala nyeri tertinggi sebelum terapi adalah nyeri sedang $(59,4 \%)$, setelah dilakukan terapi menjadi nyeri ringan $(59,4 \%)$. Hasil uji Wilcoxon pada kompres hangat rebusan jahe diperoleh $\rho=0,000$ dan kompres dingin $p=0,000$ maka H1 diterima. Sedangkan perbedaan antara uji beda dengan uji Mann Whitney diperoleh $\rho=0,389, \rho>0,05$. Kesimpulan penelitin ini adalah terdapat perbedaan efektivitas terapi kompres hangat rebusan jahe dengan kompres dingin terhadap tingkat nyeri lansia yang mengalami osteoarthritis.
\end{abstract}

Kata kunci: Dingin, Hangat, Kompres, Nyeri

\section{EFFECTIVENESS OF WARM GINGER STEW COMPRESSES THERAPY WITH COLD COMPRESSES AGAINST THE ELDERLY PAIN LEVELS EXPERIENCED \\ BY OSTEOARTHRITIS}

(Study In The Village Of The District Kaliwungu Jombang)

\begin{abstract}
Pain is the main complaint that is often felt by people with osteoarthritis. Many alternatives can be used to reduce pain, one of them is non-pharmacological methods that compress warm water of ginger stew and cold compresses. This study
\end{abstract}


has the objective to analyze the differences in the effectiveness of warm ginger stew compresses therapy with cold compresses against theelderly pain levels experienced by osteoarthritis. This type of research pre experiment with comparison group design static approuch. The population is all elderly people aged > 60 years with osteoarthritis in Kaliwungu Village, amounting to 76 people. The sampling technique used is simple random sampling with instrument observation sheet. The data are presented in the table and analyzed using the Wilcoxon Test and Mann Whitney Test. In warm compound ginger stew obtained the highest pain scale before the treatment of moderate pain (59.4\%), after therapy became mild pain (87.5\%). In the cold compress therapy group, the highest pain scale before treatment was moderate pain (59.4\%), after treatment became mild pain (59.4\%). Wilcoxon test results on warm compound ginger stew obtained $\rho=0,000$ and cold compress $p=0.000$ then H1 accepted. While differences between different test with Mann Whitney test obtained $\rho$ $=0,389, \rho>0,05$. The conclusion of this research is that there is a difference of effectiveness of warm compress therapy of ginger stew with cold compress to the elderly pain level that has osteoarthritis.

Keywords: Cold, Warm, Compress, Pain

\section{PENDAHULUAN}

Manusia yang telah mengalami perubahan fisik pada saat lansia dapat menyebabkan ketidakmampuan jaringan untuk memperbaiki diri atau mengganti jaringan yang rusak, sehingga mengalami penurunan fungsi jaringan dan menyebabkan lansia rentan terhadap berbagai penyakit. Penyakit persendian atau arthritis merupakan masalah penyakit yang sering dialami lansia. Menurut (Mulyadi, 2011 dalam Hidayat \& Ivan, 2015, 53) arthritis menempati urutan pertama penyakit kronis yang dialami oleh lansia dan sebagian besar mengalami keluhan sendi-sendinya misalkan nyeri, linu, dan pegal.

Berdasarkan hasil (Riskesdas, 2013, 94), proporsi jumlah dari populasi yang mempunyai masalah sendi pernah didiagnosis tenaga kesehatan Indonesia sebanyak 11,9\%, dimana keterkaitan yang berdasarkan gejala sebanyak 24,7\%. Proporsi jumlah dari populasi yang tertinggi dalam mempunyai masalah sendi pernah dilakukan oleh tenaga kesehatan dengan cara mendapatkan diagnosis berada pada angka (19,3\%) di Bali, Proporsi jumlah dari populasi yang tertinggi dalam mempunyai masalah sendi atas dasar gejala dengan nilai $(33,1 \%)$ didapatkan di Nusa Tenggara Timur. Penyakit sendi di Jawa Timur memiliki nilai prevalensi mencapai $27 \%$, prevalensi penyakit sendi di Kabupaten Jombang sebanyak 11.770 penderita pada tahun 2013. Studi pendahuluan dilaksanakan di Desa Ngemplak Kecamatan Diwek Kabupaten Jombang sebanyak 10 lansia yang mengalami osteoarthritis ditemukan 6 lansia mengalami nyeri berat dan 4 lansia mengalami nyeri sedang.

Penyakit osteoarthritis memiliki banyak faktor yang dapat mempengaruhinya seperti usia jenis, kelamian, geneti, olahraga, dan pekerjaan, dimana hal tersebut dapat menimbulkan dampak gangguan kenyamanan karena bisa berdampak menimbulkan rasa nyeri. (Kisworo, 2008 dalam Andarmoyo, 2013, 18) 
menyatakan bahwa dampak lain yang ditimbulkan dari osteoarthrits bisa berupa kejadian seperti rasa nyeri, keadaan mudah lelah, perubahan citra diri serta risiko tinggi terjadi cidera.

Pemberian penatalaksanaan kompres hangat rebusan jahe dan kompres dingin pada lansia yang mengalami osteoarthritis, dimana hal ini memerlukan tindakan pengkajian secara mendalam karena pengobatannya sama-sama merupakan terapi non farmakologi dalam menurunkan tingkat nyeri. Peneliti memiliki ketertarikan untuk melakukan penelitian tentang "Efektivitas Terapi Kompres Hangat Rebusan Jahe dengan Kompres Dingin terhadap Tingkat Nyeri Lansia yang Mengalami Osteoarthritis Di Kelurahan Kaliwungu Kecamatan Jombang Kabupaten Jombang".

\section{METODE PENELITIAN}

Penelitian ini merupakan penelitian eksperimen dengan menggunakan pendekatan static group comparison. Rancangan dalam penelitian ini menggunakan dua kelompok subjek yang dipilih secara acak. Kelompok perlakuan $\left(\mathrm{X}_{1}\right)$, $\left(\mathrm{X}_{2}\right)$ dan kelompok kontrol (-) dilakukan pengukuran satu kali setelah perlakukan. Efek perlakuan dilihat dari perbedaan pengukuran kedua kelompok (Saryono \& Mekar, 2013, 165).

Populasi merupakan keseluruhan objek sumber data penelitian yang diperlukan dan diteliti dalam suatu penelitian. Populasi dalam penelitian adalah seluruh lansia yang berumur $>60$ tahun yang mengalami osteoarthritis di Kelurahan Kaliwungu Kecamatan Jombang Kabupaten Jombang sebanyak 76 lansia.
Teknik sampling merupakan suatu proses seleksi sampel dengan cara menentukan jumlah sampel yang sesuai seleksi dengan kriteria dari penelitian. Peneliti menggunakan teknik sampling dengan cara probability sampling jenis simple random sampling.

(Saryono \& Mekar, 2013, 171) menyatakan bahwa sampel adalah sebagian populasi yang diambil dari keseluruhan objek penelitian dan dianggap mewakili suatu populasi. Jumlah sampel sebanyak 64 lansia yang dibagi menjadi 2 kelompok. kelompok 1 sebanyak 32 lansia dilakukan kompres hangat rebusan jahe dan kelompok 2 sebanyak 32 lansia .dilakukan kompres dingin.

Instrumen yang digunakan adalah lembar observasi dari masing-masing variabel.

\section{HASIL PENELITIAN}

\section{Data umum}

Tabel 1. Distribusi frekuensi responden berdasarkan usia pada bulan Mei 2017

\begin{tabular}{lcc}
\hline Usia (Tahun) & Jumlah & $\begin{array}{c}\text { Persentase } \\
(\boldsymbol{\%})\end{array}$ \\
\hline $60-74$ & 47 & 73,4 \\
$75-90$ & 17 & 26,6 \\
$>90$ & 0 & 0 \\
\hline Total & 64 & 100 \\
\hline
\end{tabular}

Sumber : Data primer

Sebagian besar responden berusia 60 74 tahun yaitu sebanyak 47 responden $(73,4 \%)$.

Tabel 2. Distribusi frekuensi karakteristik responden berdasarkan jenis kelamin pada bulan Mei 2017 


\begin{tabular}{lccr}
\hline Jenis kelamin & Jumlah & $\begin{array}{c}\text { Persentase } \\
(\boldsymbol{\%})\end{array}$ & H \\
\hline Laki-laki & 25 & 39,1 & se \\
Perempuan & 39 & 60,9 & \\
\hline \multicolumn{1}{c}{ Total } & 64 & 100 & T \\
\hline Sumber : Data primer & & &
\end{tabular}

Hampir setengahnya responden bekerja sebagai buruh/ petani/ pedagang yaitu sebanyak 21 responden $(32,8 \%)$.

Sebagian besar responden berjenis kelamin perempuan yaitu sebanyak 39 responden $(60,9 \%)$.

Tabel 3. Distribusi frekuensi responden berdasarkan faktor yang mempengaruhi nyeri (pengalaman masa lalu pernah mengalami osteoarthritis) pada bulan Mei 2017

Tabel 5. Distribusi frekuensi responden berdasarkan olahraga dalam sehari pada bulan Mei 2017

\begin{tabular}{ccc}
\hline $\begin{array}{c}\text { Olahraga dalam } \\
\text { sehari }\end{array}$ & Jumlah & $\begin{array}{c}\text { Persentase } \\
(\%)\end{array}$ \\
\hline Melakukan & 42 & 65,6 \\
\hline Tidak melakukan & 22 & 34,4 \\
\hline Total & 64 & 100 \\
\hline Sumber : Data primer & &
\end{tabular}

Sebagian besar responden melakukan olahraga dalam sehari yaitu sebanyak

\section{Faktor yang mempengaruhi nyeri \\ (pengalaman masa \\ lalu pernah \\ mengalami osteoarthritis)}

\begin{tabular}{lcc}
\hline Pernah & 28 & 43,8 \\
\hline Tidak pernah & 36 & 56,2 \\
\hline \multicolumn{1}{c}{ Total } & 64 & $100 \%$ \\
\hline Sumber : Data primer & &
\end{tabular}

Sebagian besar responden dengan faktor yang mempengaruhi nyeri (pengalaman masa lalu pernah mengalami osteoarthritis) mengatakan tidak pernah yaitu sebanyak 36 responden $(56,2 \%)$.

Tabel 4. Distribusi frekuensi responden berdasarkan pekerjaan pada bulan Mei 2017

\begin{tabular}{lcc}
\hline \multicolumn{1}{c}{ Pekerjaan } & Jumlah & $\begin{array}{c}\text { Persentase } \\
(\%)\end{array}$ \\
\hline Tidak bekerja & 16 & 25 \\
\hline $\begin{array}{l}\text { Buruh/Petani/Ped } \\
\text { agang }\end{array}$ & 21 & 32,8 \\
\hline Swasta & 11 & 17,2 \\
\hline Wiraswasta & 11 & 17,2 \\
\hline $\begin{array}{l}\text { Pegawai Negeri } \\
\text { Sipil }\end{array}$ & 0 & 0 \\
\hline Ibu rumah tangga & 5 & 7,8 \\
\hline \multicolumn{1}{c}{ Total } & 64 & 100 \\
\hline
\end{tabular}

Sumber : Data primer
(\%)

\section{Data khusus}

Tabel 6. Tingkat nyeri lansia yang mengalami osteoarthritis sebelum diberikan terapi kompres hangat rebusan jahe

\begin{tabular}{llcc} 
No. & $\begin{array}{l}\text { Tingkat } \\
\text { nyeri }\end{array}$ & Jumlah & $\begin{array}{c}\text { Persentase } \\
(\mathbf{\%})\end{array}$ \\
\hline 1. & Tidak nyeri & 0 & 0 \\
\hline 2. & $\begin{array}{l}\text { Nyeri } \\
\text { ringan }\end{array}$ & 10 & 31,2 \\
\hline 3. & $\begin{array}{l}\text { Nyeri } \\
\text { sedang }\end{array}$ & 19 & 59,4 \\
\hline 4. & Nyeri berat & 3 & 9,4 \\
\hline 5. & $\begin{array}{l}\text { Nyeri } \\
\text { paling } \\
\text { hebat }\end{array}$ & 0 & 0 \\
\hline & Total & 32 & $100 \%$ \\
\hline
\end{tabular}

Sumber : Data primer

Sebagian besar responden sebelum diberikan terapi kompres hangat rebusan jahe adalah nyeri sedang yaitu sebanyak 19 responden $(59,4 \%)$.

Tabel 7. Tingkat nyeri lansia yang mengalami osteoarthritis sesudah diberikan terapi kompres hangat rebusan jahe 


\begin{tabular}{llcc}
\hline No. & $\begin{array}{l}\text { Tingkat } \\
\text { nyeri }\end{array}$ & Jumlah & $\begin{array}{c}\text { Persentase } \\
(\%)\end{array}$ \\
\hline 1. & Tidak nyeri & 0 & 0 \\
\hline 2. & $\begin{array}{l}\text { Nyeri } \\
\text { ringan }\end{array}$ & 28 & 87,5 \\
\hline 3. & $\begin{array}{l}\text { Nyeri } \\
\text { sedang }\end{array}$ & 4 & 12,5 \\
\hline 4. & Nyeri berat & 0 & 0 \\
\hline 5. & $\begin{array}{l}\text { Nyeri } \\
\text { paling } \\
\text { berat }\end{array}$ & 0 & 0 \\
\hline & Total & 32 & $100 \%$ \\
\hline Sumber : Data primer & & \\
\hline
\end{tabular}

Hampir seluruhnya responden sesudah diberikan terapi kompres hangat rebusan jahe adalah nyeri ringan yaitu sebanyak 28 responden $(87,5 \%)$.

Tabel 8. Tingkat nyeri lansia yang mengalami osteoarthritis sebelum diberikan terapi kompres dingin

\begin{tabular}{llcc}
\hline No. & $\begin{array}{c}\text { Tingkat } \\
\text { nyeri }\end{array}$ & Jumlah & $\begin{array}{c}\text { Persentase } \\
(\%)\end{array}$ \\
\hline 1. & Tidak nyeri & 0 & 0 \\
\hline 2. & $\begin{array}{l}\text { Nyeri } \\
\text { ringan }\end{array}$ & 8 & 25 \\
\hline 3. & $\begin{array}{l}\text { Nyeri } \\
\text { sedang }\end{array}$ & 19 & 59,4 \\
\hline 4. & Nyeri berat & 5 & 15,6 \\
\hline 5. & $\begin{array}{l}\text { Nyeri } \\
\text { paling } \\
\text { berat }\end{array}$ & 0 & 0 \\
\hline & Total & 32 & $100 \%$ \\
\hline Sumber : Data primer & &
\end{tabular}

Sebagian besar responden sebelum diberikan terapi kompres dingin adalah nyeri sedang yaitu sebanyak 19 responden $(59,4 \%)$.

Tabel 9. Tingkat nyeri lansia yang mengalami osteoarthritis sesudah diberikan terapi kompres dingin

\begin{tabular}{llcc}
\hline No. & $\begin{array}{c}\text { Tingkat } \\
\text { nyeri }\end{array}$ & Jumlah & $\begin{array}{c}\text { Persentase } \\
(\%)\end{array}$ \\
\hline 1. & Tidak nyeri & 2 & 6,2 \\
\hline 2. & $\begin{array}{l}\text { Nyeri } \\
\text { ringan }\end{array}$ & 19 & 59,4 \\
\hline 3. & $\begin{array}{l}\text { Nyeri } \\
\text { sedang }\end{array}$ & 11 & 34,4 \\
\hline 4. & Nyeri berat & 0 & 0 \\
\hline 5. & $\begin{array}{l}\text { Nyeri } \\
\text { paling } \\
\text { berat }\end{array}$ & 0 & 0 \\
\hline & Total & 32 & $100 \%$ \\
\hline Sumber : Data primer & &
\end{tabular}

Sebagian besar responden sesudah diberikan terapi kompres dingin adalah nyeri ringan yaitu sebanyak 19 responden $(59,4 \%)$.

Tabel 10. Perbedaan efektivitas terapi kompres hangat rebusan jahe dengan kompres dingin terhadap tingkat nyeri yang mengalami osteoarthritis

\begin{tabular}{|c|c|c|c|c|c|c|}
\hline \multirow{2}{*}{ No. } & \multicolumn{3}{|c|}{$\begin{array}{c}\text { Kompres } \\
\text { hangat rebusan } \\
\text { jahe }\end{array}$} & \multicolumn{3}{|c|}{$\begin{array}{c}\text { Kompres } \\
\text { dingin }\end{array}$} \\
\hline & $\begin{array}{c}\text { Seb } \\
\text { elu } \\
\text { m }\end{array}$ & $\begin{array}{l}\text { Ses } \\
\text { ud } \\
\text { ah }\end{array}$ & $\begin{array}{c}\text { Seli } \\
\text { sih }\end{array}$ & $\begin{array}{c}\text { Seb } \\
\text { elu } \\
\text { m }\end{array}$ & $\begin{array}{l}\text { Ses } \\
\text { ud } \\
\text { ah }\end{array}$ & $\begin{array}{l}\text { Sel } \\
\text { isi } \\
\text { h }\end{array}$ \\
\hline 1. & 7 & 4 & 3 & 4 & 2 & 2 \\
\hline 2. & 4 & 2 & 2 & 4 & 2 & 2 \\
\hline 3. & 3 & 2 & 1 & 5 & 3 & 2 \\
\hline 4. & 2 & 1 & 1 & 3 & 1 & 2 \\
\hline 5. & 4 & 1 & 3 & 4 & 1 & 3 \\
\hline 6. & 4 & 3 & 1 & 6 & 4 & 2 \\
\hline 7. & 3 & 2 & 1 & 5 & 3 & 2 \\
\hline 8. & 6 & 2 & 4 & 5 & 4 & 1 \\
\hline 9. & 5 & 4 & 1 & 7 & 4 & 3 \\
\hline 10. & 4 & 2 & 2 & 3 & 2 & 1 \\
\hline 11. & 6 & 3 & 3 & 5 & 3 & 2 \\
\hline 12. & 7 & 5 & 2 & 4 & 1 & 3 \\
\hline 13. & 3 & 2 & 1 & 4 & 2 & 2 \\
\hline 14. & 2 & 1 & 1 & 4 & 3 & 1 \\
\hline 15. & 4 & 2 & 2 & 3 & 0 & 3 \\
\hline 16. & 3 & 2 & 1 & 6 & 4 & 2 \\
\hline 17. & 5 & 3 & 2 & 6 & 4 & 2 \\
\hline 18. & 4 & 3 & 1 & 3 & 1 & 2 \\
\hline 19. & 5 & 2 & 3 & 7 & 4 & 3 \\
\hline 20 & 4 & 3 & 1 & 6 & 3 & 3 \\
\hline 21. & 2 & 1 & 1 & 5 & 4 & 1 \\
\hline
\end{tabular}




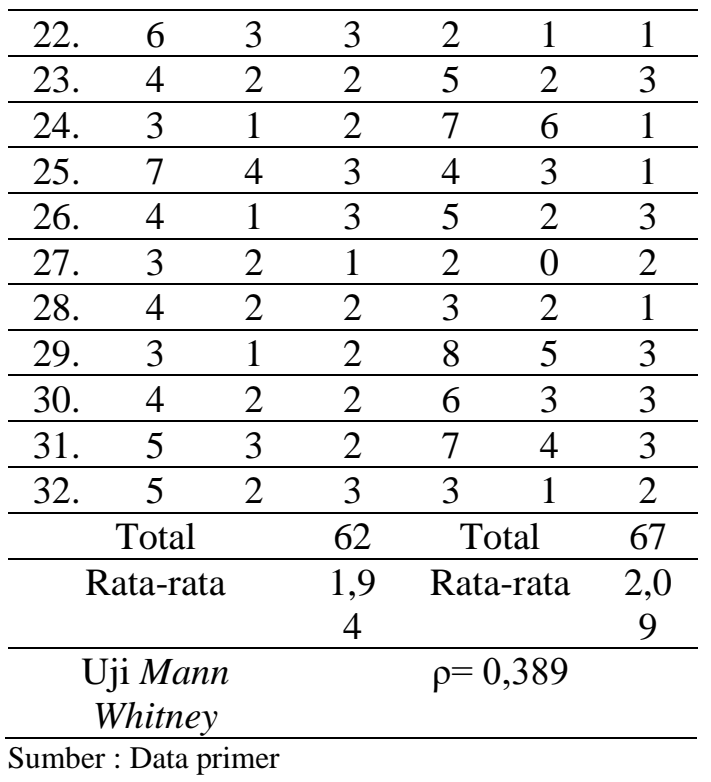

Tabel 10 menunjukkan secara deskriptif terlihat ada perbedaan terapi kompres hangat rebusan jahe dengan kompres dingin terhadap tingkat nyeri lansia yang mengalami osteoarthritis.

Hasil uji analisa menunjukkan bahwa terdapat perbedaan perbedaan efektivitas terapi kompres hangat rebusan jahe dengan kompres dingin terhadap tingkat nyeri lansia yang mengalami osteoarthris dimana $\rho=$ 0,389 maka $\rho>0,05$ sehingga hipotesis yang diberikan peneliti terbukti.

\section{PEMBAHASAN}

\section{Tingkat nyeri lansia yang mengalami osteoarthritis sebelum diberikan terapi kompres hangat rebusan jahe}

Tabel 6 diketahui bahwa tingkat nyeri lansia yang mengalami osteoarthritis sebagian besar responden sebelum diberikan terapi kompres hangat rebusan jahe adalah nyeri sedang yaitu sebanyak 19 responden $(59,4 \%)$.

Peneliti berpendapat bahwa tingkat nyeri seseorang sangat berbeda. Seseorang yang mengalami nyeri akibat osteoartritis dapat dipengaruhi beberapa faktor dimana diantaranya adalah usia dan jenis kelamin.

Menurut (JA. Roman Blas et all, 2009 dalam Suhardono et all, 2012, 10), lansia yang sudah mencapai usia $>50$ memiliki faktor resiko terjadinya penyakit nyeri, sehingga hal tersebut dapat mempengaruhi kejadian osteoarthritis.

Menurut (Ranitya, 2005 dalam Hidayat \& Ivan, 2015, 56), prevalensi osteoarthritis memiliki nilai tertinggi pada setiap masing-masing usia, dimana pada perempuan setelah mencapai > 50 tahun angka terjadinya osteoarthritis lebih tinggi dibandingkan laki-laki dan sebaliknya.

\section{Tingkat nyeri lansia yang mengalami osteoarthritis sesudah diberikan terapi kompres hangat rebusan jahe}

Berdasarkan tabel 7 diketahui bahwa tingkat nyeri lansia yang mengalami osteoarthritis tertinggi sesudah diberikan terapi kompres hangat rebusan jahe adalah nyeri ringan yaitu sebanyak 28 responden $(87,5 \%)$.

Peneliti berpendapat bahwa terapi kompres hangat rebusan jahe ini dapat memberikan suatu keadaan pada area nyeri membuat otot menjadi lebih relaksasi, sedangkan efek panas pada jahe inilah yang nantinya meredakan nyeri karena beberapa aktivitas sebagai anti radang.

Menurut (Utami, 2005 dalam Susanti, 2014, 47-48) efek panas dan pedas yang terdapat pada jahe mempunyai efek untuk menurunkan sensasi nyeri juga meningkatkan proses penyembuhan jaringan yang mengalami kerusakan, penggunaan 
panas pada jahe memberikan reaksi fisiologis.

\section{Tingkat nyeri lansia yang mengalami osteoarthritis sebelum diberikan terapi kompres dingin}

Berdasarkan tabel 8 diketahui bahwa tingkat nyeri lansia yang mengalami osteoarthritis sebagian besar responden sebelum diberikan terapi kompres dingin adalah nyeri sedang yaitu sebanyak 19 responden $(59,4 \%)$.

Peneliti berpendapat bahwa tingkat nyeri seseorang sangat berbeda. Seseorang yang mengalami nyeri akibat osteoartritis dapat dipengaruhi beberapa faktor dimana diantaranya adalah pekerjaan dan olahraga.

Menurut (Mahajan, 2005 dalam Nivasan $(2014,4)$, pekerjaan dan aktivitas yang banyak melibatkan gerakan juga merupakan salah satu penyebab osteoarthritis.

Menurut (Haq, 2003 dalam Nivasan, 2014, 5), osteoarthritis juga berhubungan dengan berbagai olahraga yang membebani lutut dan panggul, seperti petani, buruh, pedagang, sepak bola dan sebagainya.

\section{Tingkat nyeri lansia yang mengalami osteoarthritis sesudah diberikan terapi kompres dingin}

Berdasarkan tabel 9 diatas menunjukkan bahwa tingkat nyeri lansia yang mengalami osteoarthritis sebagian besar responden sesudah diberikan terapi kompres dingin adalah nyeri ringan yaitu sebanyak 19 responden $(59,4 \%)$.

Peneliti berpendapat bahwa kompres dingin menggunakan air es dapat menyebankan kondisi vasokontriksi (penyempitan pembuluh darah) sehingga saat terjadi inflamasi akan menimbulkan pengurangan pembengkakan atau nyeri.

Penelitian yang dilakukan (Kozier \& Erb, 2009 dalam Supriyadi et all, 2013, 2) menunjukkan bahwa penggunaan terapi kompres dingin memiliki efektivitas dalam meredakan nyeri dengan memperlambat kecepatan konduksi saraf dan menghambat implus saraf.

\section{Perbedaan efektivitas terapi kompres hangat rebusan jahe dengan kompres dingin terhadap tingkat nyeri lansia yang mengalami osteoarthritis}

Tabel 10 menunjukkan secara deskriptif terlihat ada perbedaan terapi kompres hangat rebusan jahe dengan kompres dingin terhadap tingkat nyeri yang mengalami osteoarthritis. Analisis penghitungan statistik menunjukkan hasil didapatkan perbedaan dimana $\rho=$ 0,389 maka $\rho>0,05$.

Peneliti berpendapat berdasarkan penghitungan hasil uji analisa statistik non parametrik dengan menggunakan uji Mann Whitney menunjukkan bahwa nilai terapi pengurangan nyeri pada kelompok terapi kompres hangat rebusan jahe dengan kelompok terapi kompres dingin ternyata tidak memiliki berbedaan yang banyak.

Penelitian (Suhardono et all, 2012, 12) yang membandingkan 2 terapi pada variabel independennya, dimana keduanya dapat menurunkan tingkat nyeri pada osteoarthritis dan menunjukkan hasil perbandingan dari kedua terapi tersebut ternyata mendapatkan hasil ada perbedaan, tetapi tidak terlalu signifikan. 
Peneliti menunjukkan hasil tabulasi bahwa nilai rata-rata jumlah beda selisih perlakuan sebelum dan sesudah terapi kompres hangat rebusan jahe adalah 1,94 dan terapi kompres dingin sebelum dan sesudah diberikan perlakuan adalah 2,09. Peneliti mendapatkan perbedaan selisih angka 0,18 dari keduanya untuk pertimbangan dalam menentukan terapi kompres yang lebih efektif dalam menurunkan tingkat nyeri. Hasil penghitungan pada tabel $\mathrm{R}$ product moment menunjukkan bahwa terapi kompres dingin lebih efektif. Peneliti memberikan saran bahwa untuk menangani masalah tingkat nyeri akibat osteoarthritis pada lansia dapat menggunakan terapi kompres dingin.

\section{KESIMPULAN DAN SARAN}

\section{Kesimpulan}

1. Tingkat nyeri lansia yang mengalami osteoarhritis terbanyak sebelum diberikan terapi kompres hangat rebusan jahe adalah sebagian besar nyeri sedang sebanyak 19 responden $(59,4 \%)$.

2. Tingkat nyeri lansia yang mengalami osteoarhritis terbanyak sesudah diberikan terapi kompres hangat rebusan jahe adalah hampir seluruhnya nyeri ringan sebanyak 28 responden $(87,5 \%)$.

3. Tingkat nyeri lansia yang mengalami osteoarhritis terbanyak sebelum diberikan terapi kompres dingin adalah sebagian besar nyeri sedang sebanyak 19 responden $(59,4 \%)$.

4. Tingkat nyeri lansia yang mengalami osteoarhritis terbanyak sesudah diberikan terapi kompres dingin adalah sebagian besar nyeri ringan sebanyak 19 responden $(59,4 \%)$.

5. Terdapat berbedaan efektivitas terapi kompres hangat rebusan jahe dengan kompres dingin terhadap tingkat nyeri lansia yang mengalami osteoarthritis dimana $\rho=0,389$.

\section{Saran}

1. Lansia

1) Menghindari kegiatan atau aktivitas fisik yang berlebihan terlalu lama, dimana hal tersebut nantinya bertujuan untuk terhindar dari resiko terjadinya osteoarthritis.

2) Lakukan terapi non farmakologi dalam mengatasi masalah nyeri akibat osteoarthritis dengan terapi kompres hangat rebusan jahe atau kompres dingin.

2. Perawat komunitas puskesmas Memberikan program penyuluhan kepada masyarakat untuk lebih memperhatikan faktor-faktor resiko terkait dengan osteoarthritis.

3. Kader lansia

Diharapkan kepada kader lansia untuk memberi pengetahuan kepada lansia yang mengalami osteoarhritis agar menggunakan terapi non farmakologi (terapi kompres hangat rebusan jahe dan kompres dingin) dalam menurunkan tingkat nyeri.

4. Peneliti selanjutnya

1) Kepada peneliti selanjutnya di harapkan dapat menentukan varibel penelitian lain yang berhubungan dengan penanganan masalah osteoarthritis pada lansia osteoarthritis. 
2) Diperlukan pemberikan intervensi secara berulang untuk mendapatkan hasil yang lebih baik.

\section{DAFTAR PUSTAKA}

Andarmoyo, S. 2013. Konsep dan Proses Keperawatan Nyeri. Jogyakarta: Ar-ruzz Media.

Hidayat, Syaifurrahman \& Ivan Dwi Arya putra. 2015. Pengaruh Terapi Kompres Jahe Terhadap Tingkat Nyeri Osteoarthritis Pada Lansia Di UPT Puskesmas Guluk-Guluk. Prodi Ilmu Keperawatan FIK Universitas Wirajaya Sumenep. Dilihat pukul 19 Februari 2017 Pukul 19.10 WIB Hal; 5359.https://www.google.co.id/?g ws rd=cr,ssl\&ei=8dL1WLmfF YKA8wWGy4SACQ\#q

http://www.depkes.go.id/Hasil-

RISKESDES-2013-

Kementrian-Kesehatan-

Republik-Indonesia. Diakses pada tanggal 19 Februari 2017 Pukul 20.10 WIB.

Nivasan, Sri. (29 Oktober 2014). Diperoleh 2 April 2017 dari https://www.scribd.com/doc/24 4891358/Gambaran-GayaHidup-Pada-PenderitaOsteoartritis-Yang-BerobatJalan-Di-Rsu-PirngadiProposal-Final-21-5-2015

Padila. 2013. Buku Ajar Keperawatan Gerontik. Yogyakarta: Nuha Medika.
Saryono \& Mekar Dwi Anggraeni. 2013. Metode Penelitian Kualitatif Dan Kuantitatif. Yogyakarta: Nuha Medika.

Suhardono et all, 2012. "Efektivitas Kompres Air Dingin Dan Kompres Air Hangat Terhadap Nyeri Pra Lansia Dengan Osteoarthritis". Sekolah Tinggi Ilmu Kesehatan Insan Cendekia Medika Jombang, Vol. 4 No.002, Hal.; 6-13

Supriyadi et all. 2013. Efektivitas Kompres Dingin Terhadap Penurunan Intensitas Nyeri Pada Pasien Fraktur Di RSUD Unggaran.

http://download.portalgaruda.or g/article.php?article $=393105 \& \mathrm{v}$ al=6378\&title $=$ EFEKTIFITAS \%20KOMPRES\%20DINGIN\% 20TERHADAP\%20PENURUN AN\%20INTENSITAS\%20NYE RI\%20PADA\%20PASIEN\%20 FRAKTUR\%20DI\%20RSUD\% 20UNGARAN diakses pada tanggal 19 Februari 2017 Pukul 20.30 WIB.

Susanti, Devi. Pengaruh Kompres Hangat Jahe Terhadap Penurunan Skla Nyeri Arthritis Remhatoid Pada Lansia Di PSTW Kasih Sayang Ibu Batu Sangkar. (Sumatera Barat: Fakultas Kesehatan Dan MIPA Universitas Muhammadiah Bukit Tinggi Sumatera Barat. 2014). 